\title{
Genital HPV infection not a local but a regional infection: experience from a female teenage group
}

\author{
P Rymark, O Forslund, B G Hansson, K Lindholm
}

\begin{abstract}
Objectives-To investigate the prevalence of human papillomavirus (HPV) infections in a group of female teenagers, and to analyse to what extent HPV DNA was also detectable, in urethra and cervix samples among the patients with macroscopic genital warts compared with those without.

Design-The patients were interviewed about their sexual habits and history of venereal diseases. They underwent a gynaecological health control examination, including macroscopic inspection for genital warts and collection of a cytological vaginal smear (Pap smear). Cell samples were also taken from endocervix and urethra and from vulva lesions, when found. These samples were tested for HPV DNA of the types 6, 11, 16, 18 and 33 using the polymerase chain reaction (PCR) technique.
\end{abstract}

Setting-An adolescence out-patient clinic in Malmö, Sweden.

Subjects-Forty-nine female teenagers consulting for gynaecological complaints, some of them for genital warts.

Results-Twenty patients had present and four had a history of genital warts (group A). The other 25 patients had no visible lesions (group $B$ ). In the first group (A) 18 of the 24 patients were positive for HPV DNA in one or more of the three locations studied. More patients were positive in urethra (17) than in cervix (15). In group $B$ four of the 25 patients were positive for HPV DNA in urethra, three of these also in cervix. In the two groups 11 and four patients, respectively, showed pathological Pap smears.

Conclusions-The finding of HPV DNA in urethra, both from women with and without visible genital warts, indicates that there is a high probability that the infection is also present in cervix, suggesting that the genital HPV infections are multifocal. Thus, patients with genital warts are most likely to have cervical HPV infections and will more often have pathological Pap smears than patients without warts.

(Genitourin Med 1993;69:18-22)

Introduction

Infections with certain types of human papil- lomaviruses (HPV) belong to the group of sexually transmitted diseases (STD). The association between infections with some HPV types, the most important one being type 16, and cervical intraepithelial neoplasia (CIN) and cancer has now been well documented. ${ }^{1-3}$ Other HPV types, such as 6 and 11 cause anogenital condylomata. Early sexual experience and a high number of life time sex partners correlate with increased prevalence of HPV infections ${ }^{45}$ and CIN. ${ }^{6}$ Incentives for the growing interest in HPV research have been the availability of more sensitive and specific diagnostic methods, such as the polymerase chain reaction (PCR), and the observation of increasing incidence of genital warts and CIN over the last ten years. ${ }^{7}$ Also, Pap smears from young individuals have shown an alarmingly high incidence of cervical abnormality by cytology. ${ }^{8}$

In the present study, the simultaneous occurrence of HPV DNA in cervix and urethra was investigated and compared with cytological vaginal smears in two groups with and without macroscopical genital warts. Interview about sexual habits was used to identify those female teenagers with increased risk to acquire STD.

\section{Materials and methods}

Adolescence clinic

In the city of Malmö (population 250 000) in the south of Sweden there are two adolescence clinics, where young people, up to 20-21 years of age, can consult medical personnel or social workers. One of the main tasks for the adolescence clinics is to inform about STD, especially HIV/AIDS. Visits to the clinics are without cost to the patients, but they have to pay for birth control pills and most of the medications prescribed. Among teenagers the clinics are often well known and have excellent reputation. This reputation is a very important tool and a part of the image of the clinics. Recommendation to visit an adolescence clinic is often a hearsay from a teenage friend or school nurse.

Patients. Female teenagers without current menstrual bleeding, but otherwise randomly selected from those with appointments to the gynaecologist, were invited to participate. Two patients rejected because they were afraid that "the test was painful". Many patients had a history of STD, genital warts or a partner with genital warts. All patients were examined and all test specimens were 
Table 1 Nucleotide sequences of primers and probes used in PCR test for HPV DNA.

\begin{tabular}{|c|c|c|}
\hline Gene & Sequence & Ref \\
\hline HPV 6 L2 & 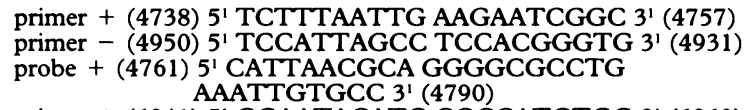 & 10 \\
\hline HPV $11 \mathrm{LJ}$ & $\begin{array}{l}\text { primer }+(6841) 5^{\prime} \text { GGAATACATG CGCCATGTGG } 3^{\prime}(6860) \\
\text { primer }-(7057) 5^{\prime} \text { AGGTGTGGGT TTCTGACAGG } 3^{\prime}(7038) \\
\text { probe }+(6978) 5^{\prime} \text { CGCCTCCACC AAATGGTACA } \\
\text { CTGGAGGATA } 3^{\prime}(7107)\end{array}$ & 11 \\
\hline HPV 16 E6 & $\begin{array}{l}\text { primer }+(320) 5^{\prime} \text { ATTAGTGAGT ATAGACATTA } 3^{\prime}(339) \\
\text { primer }-(429) 5^{\prime} \text { GGCTTTTGAC AGTTAATACA } 3^{\prime}(410) \\
\text { probe }+(354) 5^{\prime} \text { GTGGAACAAC ATTAGAACAG } \\
\text { CAATACAACA AACCGTTGTG } 3^{\prime}(393)\end{array}$ & 12 \\
\hline HPV 18 E6 & $\begin{array}{l}\text { primer }+(328) 5^{1} \text { ATTAGAGAAT TAAGACATTA } 31(347) \\
\text { primer - (437) 5' GGTTTCTGGC ACCGCAGGCA } 3^{1}(418) \\
\text { probe }+(362) 5^{1} \text { ATGGAGACAC ATTGGAAAAA }\end{array}$ & 13 \\
\hline HPV $33 \mathrm{El}$ & $\begin{array}{c}\text { primer }+(2415) 5^{1} \text { ATGATAGATG ATGTAACGCC } 31(2434) \\
\text { primer }-(2795) 5^{1} \text { AGTA TTTTCT CCTGCACTGC } 3^{\prime}(2776) \\
\text { probe }+(2560) 5^{\prime} \text { CAAATGCAGG CACAGACTCT } \\
\text { AGATGGCCAT 3' } \\
\text { AG89) }\end{array}$ & 14 \\
\hline
\end{tabular}

taken by the same gynaecologist. In connection with the examination the patients were interviewed by a female nurse.

The participants were divided into two groups: group A consisting of 20 patients with macroscopic genital warts (condyloma acuminata) of the vulva plus four with history of earlier vulva warts, and group B with 25 patients without visible or known history of genital warts. Vulvoscopy or colposcopy was not performed.

\section{Samples}

A speculum was inserted into the vagina, and after macroscopic inspection ordinary Pap smears were taken from vagina and ectocervix with a wooden spatula and from endocervix with a brush (Cytobrush, Medscand, Sweden). With the speculum still in vagina, cell samples for HPV DNA analysis were collected from the endocervix using the Cytobrush. Cell sample from urethra was collected with a cotton swab and from visible warts (lesions) with the use of the Cytobrush. All samples were collected strictly in this order. Two of the patients with a history of vulval condylomata but with no visible warts had a test from the previous wart area, as identified by the patients. Discomfort was felt only from the urethra sampling, being equivalent to a chlamydia test. Samples for gonococci and chlamydia were not taken. Patients with pathological Pap smears were subject to a second examination and cell sampling approximately three months later.

\section{HPV DNA analysis by polymerase chain reaction (PCR). ${ }^{9}$}

The cell samples for HPV DNA tests were suspended in physiological saline and then sent to the laboratory. After being pelleted by centrifugation $(4000 \times \mathrm{g}, 5 \mathrm{~min})$ the cells were digested by proteinase $\mathrm{K}(1.6 \mathrm{mg} / \mathrm{ml})$ overnight at $37^{\circ} \mathrm{C}$. After heat inactivation of the proteinase (boiling for $10 \mathrm{~min}$ ) $5 \mu \mathrm{l}$ of each sample was added to two tubes with $45 \mu \mathrm{l} \mathrm{PCR}$ mix containing $200 \mu \mathrm{M}$ of each dNTP (Boehringer Mannheim) and 1.25 U Taq DNA polymerase and reaction buffer (Promega). To one of the tubes oligonucleotide primers specific for HPV DNA 6, 11 and 33 and to the other tube primers for HPV 16 and 18 were included, each at a concentration of $0.75 \mu \mathrm{M}$. The type specific DNA primers and probes were chosen and synthesised from published nucleotide sequences (table 1). The PCR reaction with the HPV 6,11 and 33 primers was run in a Hybaid thermal reactor with a $4.5 \mathrm{~min}$ initial denaturation step at $94^{\circ} \mathrm{C}$, then 30 cycles with $94^{\circ} \mathrm{C}$ for $30 \mathrm{~s}$ (denaturation), $50^{\circ} \mathrm{C}$ for $30 \mathrm{~s}$ (annealing) and $72^{\circ} \mathrm{C}$ for $45 \mathrm{~s}$ (extension). After the last cycle, 5 min extra extension time was added. PCR with the HPV 16 and 18 primers was performed as above, except that $45^{\circ} \mathrm{C}$ was used as annealing temperature and that the $72^{\circ} \mathrm{C}$ extension step was omitted owing to the short length of the amplified DNA fragment. Purified, cloned DNA of all the five HPV types ( $5 \mathrm{fg}$ of HPV 16 and $50 \mathrm{fg}$ of the other types) was used as positive controls. Human lung fibroblasts and PCR mix without any DNA template served as negative controls.

In order to identify HPV DNA sequences, the amplified samples were denatured with $\mathrm{NaOH}$ and EDTA (final concentration $0.6 \mathrm{M}$ and $37 \mathrm{mM}$, respectively) for $15 \mathrm{~min}$ and transferred to three (from primer mix HPV 6, 11 and 33) and two (from primer mix HPV 16 and 18) nylon membranes (Gene Screen Plus, Du Pont) prewetted in $6 \times \operatorname{SSC}(1 \times$ SSC: $0 \cdot 15 \mathrm{M} \mathrm{NaCl}, 15 \mathrm{mM}$ Na-citrate, pH 7) using a special manifold (Schleicher \& Schüll). The membranes were neutralised with $250 \mu 120 \times$ SSPE $(1 \times$ SSPE: $0 \cdot 18 \mathrm{M}$ $\mathrm{NaCl}, 10 \mathrm{mM} \mathrm{NaH} \mathrm{PO}_{4}, 1 \mathrm{mM}$ EDTA, pH $7 \cdot 0$ ). Thereafter, the five membranes were prehybridised separately in a solution containing $50 \%$ deionised formamide, $1 \%$ SDS, $10 \%$ dextran sulphate, $1 \mathrm{M} \mathrm{NaCI}$ and $100 \mu \mathrm{g} / \mathrm{ml}$ of herring sperm DNA at $42^{\circ} \mathrm{C}$ for $1 \mathrm{~h}$ in a hybridisation oven (Hybaid). Each membrane was then hybridised in the same mix with the addition of one of the HPV type-specific DNA probes, 3' end-labelled with ${ }^{32} \mathrm{P}$ to a specific activity of $\sim 10^{8} \mathrm{CPM} / \mu \mathrm{g}$. After incubation for one hour, the membranes were rinsed once quickly and then for $3 \times 15$ min with $2 \times$ SSPE plus $0.1 \%$ SDS at $65^{\circ} \mathrm{C}$. Finally, autoradiography was performed with the membranes exposing an X- 
Table 2 Characteristics of 24 teenage female patients with present or a history of genital warts (group $A$ ) and 25 without (group B)

\begin{tabular}{lll}
\hline & Group $A$ & Group $B$ \\
\hline Number of patients & 24 & 25 \\
Age, mean & $18 \cdot 6$ & $18 \cdot 3$ \\
range & $16-21$ & $15-21$ \\
Age at menarche & $12 \cdot 8$ & $12 \cdot 4$ \\
Age at first intercourse & $15 \cdot 3$ & $15 \cdot 1$ \\
No of sexual partners, mean & $6 \cdot 0$ & $4 \cdot 3$ \\
$\quad$ range & $2-20$ & $2-10$ \\
No of life time sex partners of & & \\
the patient's present partner, mean & $10 \cdot 9^{\star}$ & $6 \cdot 3^{\star}$ \\
range & $2-30$ & $1-35$ \\
\hline${ }^{\star} p<0.05$. & & \\
\end{tabular}

ray film (Kodak X-AR) in a cassette with intensifying screens (Cronex lightning plus, Du Pont) for $1-3$ days at $-70^{\circ} \mathrm{C}$. Samples were taken to be positive when definite spots of darkening of the film could be distinguished from the background signal of the
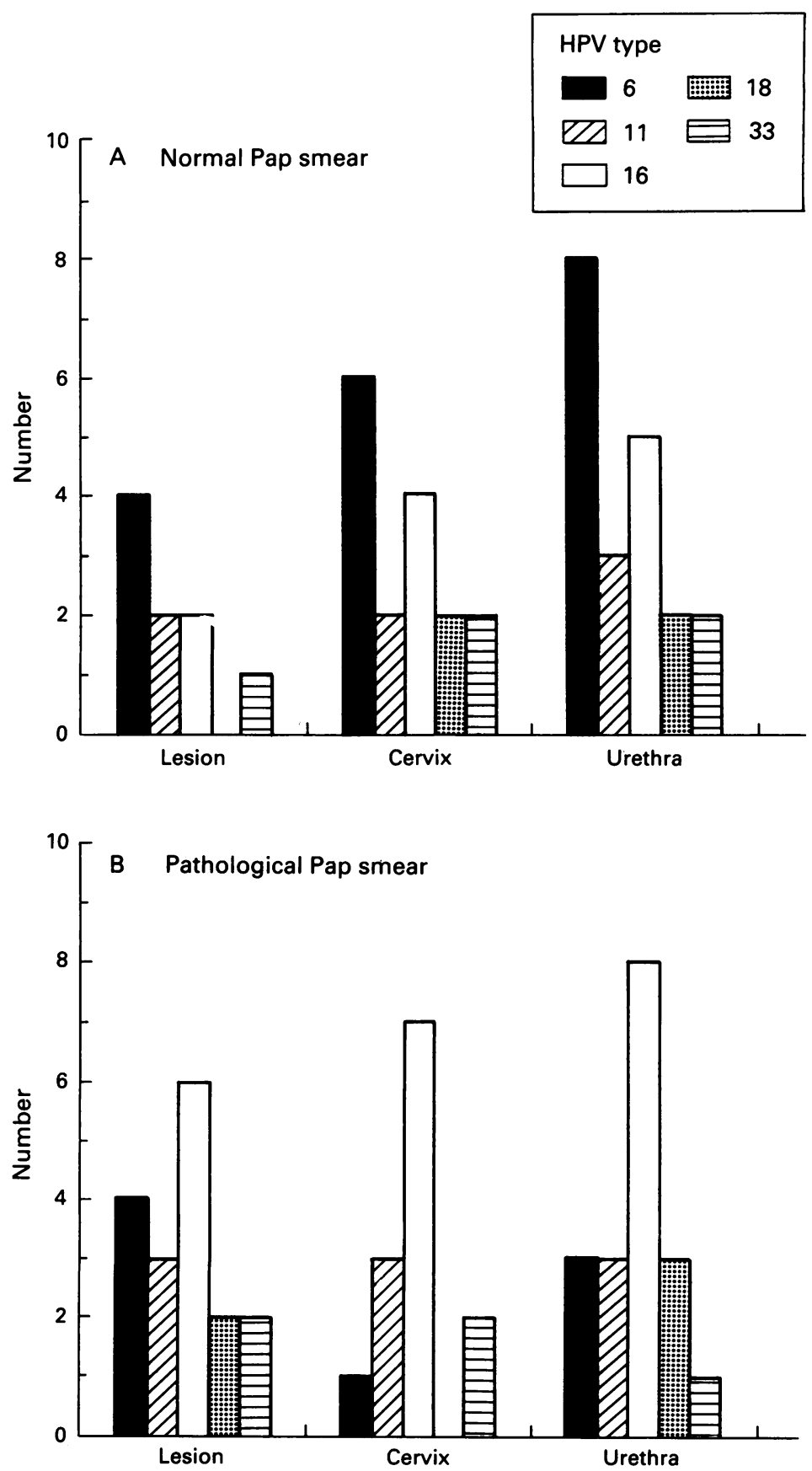

HPV DNA found at different locations in patients with a) normal Pap smears $(n \times 33)$ and b) pathological Pap smears $(n \times 15)$. negative controls. Using this design of the PCR-hybridisation technique as little as three HPV 16 genomes could be detected. In order to eliminate the risk of false positive results due to cross-contaminations, the handling of the reagents, patient materials and amplified products were done in three separate rooms. All pipettings were done with positive displacement pipettes (Microman, Gilson). Also, the overlay of paraffin oil in the PCR tubes was applied to the reagent mix before the patient material was added.

\section{Statistical analyses}

Differences in HPV prevalence between the groups were evaluated using the Fisher's exact test and the Mann-Whitney U test.

\section{Results}

The age of the patients, their age at sexual debut and the number of life time sexual partners were similar in the two groups of patients. There was a wide range in the number of partners, from two to twenty, and in the estimated total number of coitus, from ten to 750 , but with no differences between the two groups. The mean number of life time sexual partners of the group A patients' present partners was significantly higher than that of the partners of the group B patients, 10.9 versus $6.3(p<0.05)$ (table 2$)$

Among the 24 patients with current or previous condylomata (group A) $18(75 \%)$ were shown to harbour HPV infections in one or more locations. Fifteen (63\%) of the cervix and $17(71 \%)$ of the urethra samples contained HPV DNA. Fourteen patients were positive for HPV DNA both in cervix and urethra and in all cases at least one HPV type was the same at both sites. Eleven patients had identical combinations of HPV types in urethra and cervix. In samples collected from the lesions of 19 patients $13(68 \%)$ were positive. Twelve $(63 \%)$ of the 19 patients were positive for HPV DNA in all three locations, four of the 24 patients were positive in two and in two of the patients HPV DNA was detected in only one site. Eleven $(46 \%)$ of the patients of group A had pathological Pap smears, ten classified as CIN 1 and one as CIN 2. All of these patients were positive for HPV DNA except for one with CIN 1 diagnosis.

Four (16\%) of the 25 patients of group B were positive for HPV DNA, three in both

Table 3 HPV DNA and Pap smear results in 24 female patients with present or a history of genital warts (group $A$ ) and 25 without (group B)

\begin{tabular}{lll}
\hline & Group $A$ & Group $B$ \\
\hline HPV DNA positive any site & $18^{\star}$ & $4^{\star}$ \\
HPV DNA cervix & $15^{\star}$ & $3^{\star}$ \\
$\quad$ urethra & $17^{\star}$ & $4^{\star}$ \\
$\quad$ cervix and urethra & $14^{\star}$ & $3^{\star}$ \\
Identical combination of HPV types & $11^{\star}$ & $2^{\star}$ \\
in cervix and urethra & $11^{\star}$ & \\
$\quad$ cervix and urethra & $12^{\star}$ & \\
Pathological Pap smear & $11^{\star}$ & $4^{\star}$ \\
\hline
\end{tabular}

${ }^{\star} \mathrm{p}<0.02$ 
cervix and urethra and one in the urethra sample only. Two patients had identical HPV types in urethra and cervix. Pathological Pap smear was found in four (16\%) patients, CIN 1 in three, all HPV DNA negative, and CIN 2 in one patient, who was positive for both HPV 16 and 18 DNA. Pap smear from one of the group B patients was missing. Infection with more than one HPV type was most common, 14 of 22 patients had two or more types simultaneously (table 3 ).

Of the total of 49 patients in the study, Pap smears were available from 48,33 being normal and 15 pathological. In the group with normal Pap smears HPV DNA was found in one or more sites of sampling in $11(32 \%)$ and among those with pathological Pap smears $11(73 \%)$ were positive for $\mathrm{HPV}$ DNA. The figure shows the number of samples positive for the various HPV types tested for, grouped into patients with normal and pathological Pap smears, respectively. In the normal group HPV 6 was the predominant type in both lesion, cervix and urethra samples followed by HPV 16. Among the patients with pathological Pap smears HPV 16 was the predominant one in all three sites.

As a quality control a senior cytotechnologist without knowledge of the initial results rescreened all the Pap smears. Out of the 33 benign cases 31 were rescreened as benign and two as CIN 1. In the group with pathological Pap smears nine out of the 13 reported as CIN 1 were rescreened as such, one as CIN 2 and three as benign but with cellular changes in agreement with HPV infection. The two cases primarily reported as CIN 2 were rescreened as CIN 2 and CIN 3, respectively.

The patients with abnormal cytology at first examination were followed up with new Pap smears approximately three months later. Of those 13 patients with CIN 1 at the initial test, six showed CIN 1, one CIN 3 and six had normal cytology at the second test. HPV DNA was detected in five, one and three of the patients in the respective groups. The two women with CIN 2 diagnosis at the first examination showed $\mathrm{CIN} 1$ and CIN 2 at the second examination.

\section{Discussion}

The female teenagers who participated in this study are not representative for all teenagers in Malmö or Sweden. Both groups, with and without visible condylomata, came from a sub-population probably with earlier sexual debut, higher number of partners and higher prevalence of sexually transmitted diseases than the general population. Furthermore, many of the patients visited the adolescence clinic because of suspected genital warts. The age at first intercourse was equal to a group of patients treated for chlamydia infections at the same clinic (Ericsson, C., personal communication). The number of sexual partners ranged from two to twenty, but there was no difference between those with and without visible warts. However, the mean estimated number of life time sexual partners of the group A patients' present partners was significantly higher than that of the patients of group B, stressing that not only the woman's sexual experience but also the sexual history of her partner is very important.

Despite all STD information and campaigns to use condoms as protection against infections ("safe sex"), condom use is not common among the teenagers. The majority of the girls use birth control pills, and it is difficult to motivate both female and male teenagers to use condoms as prophylaxis against STD infections.

The combined use of acetic acid application and vulvoscopy/colposcopy at the examination of the patients would probably have identified some individuals with suspected HPV lesions in group B. However, all acetowhite lesions are not due to HPV infections. ${ }^{1516}$ In order to minimise the discomfort to the patients, we therefore chose not to perform colposcopy but to group the patients according to the presence or absence of macroscopic genital warts.

False positive results were pitfalls associated with the use of the PCR technique after its introduction. However, with special measurements taken such as strictly separated working areas for clean reagents, patient material and for amplified material and the use of pipettes with special tips with filters, PCR has become a most specific and reliable technique. It is also important to include many negative controls in the test. Questions about possible cross-contamination between samples collected from different patients, caused by aerosol in the examination room, have been raised. However, in an investigation performed at a colposcopy clinic, where more than half of the patients had genital HPV infections, HPV DNA could neither be detected in swab samples collected daily during one week from both the examination table and the floor, nor from tubes with saline left open in the room during the day (Forslund $e t$ al, unpublished).

Although it is not possible in every single case to rule out that local contamination from the cervix to urethra might have taken place during the examination, despite digital separation of labia minor and insertion of the speculum in a vertical-down movement, it seems unlikely to be an explanation of the HPV DNA findings from urethra. The reliability of the urethra HPV DNA results is further supported by results from analysis of urine specimens and urethra brush samples collected in this order from both men and women, showing good correlation between the HPV DNA findings of the paired samples (Forslund, O., to be published).

In patient group $A$, where the prevalence of HPV DNA was much higher (75\%) than in group B $(16 \%)$, the prevalence of pathological Pap smears was also much higher compared with group B, $46 \%$ and $16 \%$, respectively, confirming the correlation between HPV infections, condylomata and cervical dysplasia. HPV 16, the main malig- 
nancy associated HPV type, predominated among the patients with abnormal Pap smears, and was the most common type in all three locations analysed (fig b). In the group with normal Pap smears HPV 6 was the single most common type, although infections with HPV16, 18 and 33 taken together were almost as prevalent as HPV 6 and 11 together (fig a). There was a good agreement between the cytological primary screening and the rescreening. All cases reported as CIN 1 or benign with cellular changes associated with HPV infection would have been classified as squamous intraepithelial lesion (SIL), low grade, according to the suggested Bethesda system. ${ }^{17}$

From our data it is apparent that the HPV infections in patients with condylomata acuminata not only are present in the visible warts and the area around them, but are also often found in the cervix uteri and in the urethra. Since parallel findings of HPV DNA in these sites, generally with one or more types in common, were most prevalent, the detection of HPV infection in one genital location makes it highly probable that the same type of HPV is present in other genital sites, too. Subclinical HPV infections of the vulva have also been found to coexist in high frequency with HPV infections and precancerous lesions of the cervix. ${ }^{18}$ Thus, the HPV infection in the genitourinary tract, in this sense, is most often not only a local but a regional or multifocal infection.

When HPV DNA can be detected in urethra cell samples collected with a brush or a swab, as in this study, the same HPV type can generally also be found in cells from urine specimens from the same patient (Forslund, O. et al, manuscript in preparation). Therefore, at least in epidemiological surveys, HPV DNA analysis of urine might become a convenient, non-invasive method of choice applicatory to individuals of all ages.

There are still many unanswered questions regarding the implications of genital HPV infections. Can treatment of a condyloma of the vulva change the prognosis of the patient, when the infection is also present in other sites such as urethra and cervix? To which extent should the type of HPV influence treatment and follow up of the infection? What happens when condylomata disappear after laser therapy? Is the immune response against the viral infection activated? How should the male partners to HPV infected women be approached? Should they be tested, and if found HPV positive, can and should they be treated?

To investigate the long time effects of genital HPV infections, the female teenage patients of this study will be followed longitudinally concerning cytological changes and presence of HPV DNA.

We are grateful to Inger Lundius, trained nurse at the Adolescence Clinic, who carried out all the interviews. The project was supported by grants from Malmö General Hospital Cancer Foundation and the local programme for the defeat of HIV/AIDS.

1 Ambros RA, Kurman RJ. Current concepts in the relationship of human papillomavirus infection to the pathogenesis and classification of precancerous squamous lesions of the uterine cervix. Semin Diagn Pathol 1990;7:158-72.

2 Battista C, Hillova J, Hil M, Reynes M, Mathe G Presence of human papilloma virus types 16 and 18 in Presence of human papilloma virus types 16 and 18 in Pharmacother 1988;5:1-9.

3 Syriänen KJ. Epidemiology of human papillomavirus (HPV) infections and their associations with genital squamous cell cancer. Review article. APMIS 1989, 97:957-70.

4 Azocar J, Abad SM, Acosta $\mathrm{H}$, et al. Prevalence of cervica dysplasia and HPV infection according to sexual behavior. Int $\mathcal{F}$ Cancer 1990;45:622-5.

5 Herrero R, Brinton LA, Reeves WC, et al. Sexual behavior, venereal diseases, hygiene practices, and invasive cervical cancer in a high-risk population. Cancer 1990,65:380-6.

6 Moscicki AB, Winkler B, Irwin CJ, Schachter J Differences in biologic maturation, sexual behavior, and sexually transmitted disease between adolescents with and without cervical intraepithelial neoplasia. $¥$ Pediat 1989;115:487-93.

7 Learmonth GM, Durcan CM, Beck JD. The changing incidence of cervical intra-epithelial neoplasia $S$ Afr Med F 1990;77:637-9.

8 Larsen PM, Vetner M, Hansen K, Fey SJ. Future trends in cervical cancer. Cancer Lett 1988;41:123-37.

9 Saiki RK, Gelfand DH, Stoffel S, et al. Primer directed enzymatic amplification of DNA with a thermostable DNA polymerase. Science 1988;239:487-91.

10 Schwarz E, Durst M, Demankowski C, et al. DNA sequence and genome organization of genital human papillomavirus type 6b. EMBO ₹ 1983;2:2341-8.

11 Dartmann K, Schwarz E, Gissman L, zur Hausen H. The nucleotide sequence and genome organization of human papilloma virus type 11. Virology 1986;151:124-30.

12 Shibata DK, Amheim N, Martin W J. Detection of human papilloma virus in paraffin-embedded tissue human papiloma virus in paraffin-embedded tissue

13 Cole ST, Danos O. Nucleotide sequence and comparative analysis of the human papillomavirus type 18 genome. Mol Biol 1987;193:599-608.

14 Cole ST, Streeck RE. Genome organization and nucleotide sequence of human papillomavirus type 33, which is associated with cervical cancer. $\mathcal{F}$ Virol 1986, 58:991-5.

15 Schultz R E, Miller JW, MacDonald GR, et al. Clinical and molecular evaluation of acetowhite genital lesions in men. F Urol 1990;143:920-3.

16 Wikstrom A, Hedblad M-A, Johansson B, et al. The acetic acid test in evaluation of subclinical genital papillomavirus infection: A comparative study on peniscopy, histopathology, virology and study on peniscopy, histopathology, virology and scanning electron
microscopy findings. Genitourin Med 1992;68:90-9.

17 The 1988 Bethesda system for reporting cervical/vaginal cytologic diagnosis. Acta Cytol 1989;33:567-71.

18 Kulski JK, Demeter T, Rakoczy P, Sterrett GF, Pixley EC. Human papillomavirus coinfections of the vulva and uterine cervix. $\mathcal{f}$ Med Virol 1989;27:244-51. 